\title{
Protection of humanity's cultural and historic heritage in space
}

\author{
Justin St. P. Walsh* \\ Department of Art, Chapman University, One University Drive, Orange, CA 92866, USA
}

\section{A R T I C L E I N F O}

\section{Article history:}

Received 30 November 2011

Received in revised form

11 April 2012

Accepted 16 April 2012

Available online $\mathrm{xxx}$

\begin{abstract}
A B S T R A C T
While the international community has acted forcefully since World War II to protect sites and objects of cultural or historic significance on Earth, little attention has been paid to the same kinds of sites and objects in space. There are important ethical and scholarly reasons for wanting to preserve sites and in situ objects in off-Earth contexts from destruction or commercial exploitation. Innovative space research equipment, such as spacecraft, satellites, and space stations, and the locations of historic missions, such as Tranquility Base, therefore deserve formal international recognition and protection. Appropriate models for developing a comprehensive protective scheme can be found in existing international protocols, especially the 1959 Antarctic Treaty (and later additions), the 1970 UNESCO Convention on Cultural Property, the 1972 UNESCO World Heritage Convention, and the 2001 UNESCO Convention on the Underwater Cultural Heritage. In addition, space agencies and professional organizations can mandate adequate and ethical planning for the post-operational phases of space missions to include arrangements for heritage protection.
\end{abstract}

(ㄷ) 2012 Elsevier Ltd. All rights reserved.

\section{Introduction}

Legal and ethical issues related to the management of heritage have attracted increasing attention from scholars and governments since the Second World War. The rapidly growing literature on the subject of heritage represents the interests of various stakeholders - not only governments and scholars, but also museums, private collectors, dealers, lawyers, and indigenous groups, among others [1-10]. Specific major developments have included the restitution of art looted in wartime, the recognition of the rights of previously disenfranchised populations to have their heritage respected and for them to determine how it will be preserved, and the protection and preservation of sensitive sites and monuments. Under the aegis of its Educational, Scientific and Cultural Organization (UNESCO), the United Nations has created systems for recognizing sites of extraordinary importance. By November 2011 UNESCO had recognized 936 sites ( 725 cultural, 183 natural, and 28 mixed) in 153 state parties on its World Heritage List [11]. National governments have also enacted legislation to manage and protect their heritage, and signed international agreements to control the transport and sale of cultural heritage across borders. The actions that have been taken up to this point have neglected extra-terrestrial heritage, however, even though some of humanity's most significant recent

\footnotetext{
* Tel.: +1 714628 7376; fax: +1 7149976744 .

E-mail address: jstpwalsh@chapman.edu.
}

accomplishments have happened in space. The special nature of space obviously presents environmental and legal challenges for the preservation of objects and sites located off-planet. Existing treaties recognize that space is a territory that all nations have the right to explore, but no nation may exercise sovereignty over, while each one retains jurisdiction over the objects it has placed there and registered with the UN Office for Outer Space Affairs. These challenges are unusual, but not unique to space. Significant international precedents exist in other contexts to suggest a solution.

This paper will lay out some ideas about what kinds of heritage might need protecting in space, how contemporary understandings of heritage might be relevant to space research, and how heritage management relates to the development of legal regimes for private and public activity in space. It will begin by defining extraterrestrial cultural heritage as something different from normal scientific, military, or commercial equipment. It will show how humanity as a whole has embraced the historic events and objects associated with space research as part of our jointly held heritage. An outline will be provided for the history of the concept of heritage on Earth, and why it is important, both as an ethical concern and as an academic one, that, when heritage is identified, it is preserved. Finally, the paper will conclude with some suggestions for steps that can be taken by space scientists, their professional organizations, and the international community to recognize the importance of cultural heritage, to integrate such an understanding into future research, and to engage with a larger public (and human community) that admires the achievements of space science. 


\section{Space heritage or space junk?}

The human history of direct exploration of space began in 1957 , with the launch of Sputnik by the USSR, and has continued apace to the present. The oldest human object still in space is the American satellite Vanguard 1, which was launched in March 1958 [12]. Space development has been a global endeavor. At least 12 different nations and the multinational European Space Agency (ESA) have now launched satellites into space (counting Russia, Kazakhstan, and the Ukraine separately from the USSR; North Korea's claimed launches have been disputed and are not included in this count). Several other nations such as Italy, Australia, and Kenya have launch sites, landing areas, and tracking centers for space missions. Five nations and the ESA have placed objects on the Moon, three nations have placed objects on Mars, and public space agencies and private corporations located around the world are currently engaged in various stages of preparing missions.

\subsection{Space objects as "junk"}

Older objects in space can be viewed in a number of different ways. One popular contemporary vision of humanmade objects in space can be called the "space objects as junk" view. Many of the objects sent into space (and left there, or abandoned to destruction on re-entry) can be seen simply as tools of a kind that either become obsolete as technology progresses, or that are no longer used because they break. The objects become garbage, obstacles, even dangers for the present and future. Indeed, many groups, including the JAXA Space Technology Research Centre, the Swiss École Polytechnique Fédérale de Lausanne, and NASA have carried out significant research on active removal of existing space debris [13-15]. The US Air Force's Joint Space Operations Command currently claims to be tracking over 22,000 pieces (defined as larger than $10 \mathrm{~cm}$ ), along with an estimated half-million more pieces between 1 and $10 \mathrm{~cm}$ in size [16]. It must be admitted that these enormous numbers make it hard to consider the overwhelming majority of orbiting equipment, or fragments of equipment, as anything other than undifferentiated, purely utilitarian, and thus beneath consideration for preservation. Most objects in space are not very significant, or even necessarily significant at all.

\subsection{Space objects as "heritage"}

There is another way of considering at least some of these objects, however. Space objects that display innovation, especially those that remain intact, can be seen as critical evidence for the development of humanity and, indeed, as part of our heritage. Neil Armstrong's remark upon setting foot on the Moon on 20 July 1969 is not only evocative, but undoubtedly relevant: "[That's] one small step for man; one giant leap for mankind." Although it may seem unusual to regard things made and used within our own lifetimes as "heritage", it is clear that humans do, in fact, already think of some space objects as culturally and/or historically important, and that we even treat these objects accordingly. Several pieces of evidence support this view. First, there are many significant public collections of natural and humanmade objects related to space research located around the world, and numerous private collectors are interested in such objects; some of these collectors are willing to pay extremely large sums of money for them [17]. Scholars have embarked on the study of human endeavors in space as history $[18,19]$.The most famous venue is surely the Smithsonian Institution's National Air and Space Museum (NASM) in Washington, which holds and displays, among other important pieces, capsules from the Mercury, Gemini, and Apollo programs, a full-scale replica of a Soviet Soyuz module (docked with a test Apollo command-service module), a mock-up of the Skylab space station, early satellites, and a real Apollo lunar module - the only one that was never used on a mission. One of the most popular exhibits is a piece of lunar rock which visitors can touch. One way of gauging public interest in space heritage is by calculating attendance at museums like NASM. According to the museum, there were $8,340,932$ visitors to its main building on the Mall in 2010 [20]. This number would put NASM in second place worldwide when compared to international art museums, just behind the Musée du Louvre ( 8.5 million visitors) and substantially ahead of the next closest institution, the British Museum (5.8 million) [21]. When the number for the main NASM building is combined with the 2010 attendance figure of 1,120,449 for its satellite campus, the Stephen F. Udvar-Hazy Center (located adjacent to Dulles International Airport in Washington's Virginia suburbs) the total is $9,461,381$ - very likely the largest number of visitors to a historic collection of any kind anywhere in the world. Since opening in 1976 , NASM has averaged 8.6 million total visitors a year.

Space museums elsewhere have large numbers of visitors, too: the Russian Tourist Board reports that the Memorial Museum of Cosmonautics in Moscow, which has 85,000 items in its collection, receives 300,000 annual visitors [22]. In 1996, France's Centre National d'Études Spatiales opened a museum at its spaceport in French Guiana, and NASA has offered paid tours of the Kennedy Space Center in Florida for several decades. Images generated by space missions have even been acquired by prestigious fine-art museums: a mosaic of photographs produced from images sent back to Earth from the Moon by a NASA Surveyor probe in 1967 is in the permanent collection of the Metropolitan Museum of Art (inv. 1992.5153), where it was recently on display in a specially-curated exhibition called, "From Here to There: Passages in Contemporary Photography", alongside important works by well-known twentieth-century art photographers.

Another example of space-based sites and objects being considered heritage can be found in the rules of the ongoing Google Lunar X Prize, which offers $\$ 20$ million to the first private team to land a rover on the Moon, travel $500 \mathrm{~m}$, and send back video to Earth. The competition includes a "Heritage Bonus" of unspecified amount (probably around $\$ 1$ million) [23]. In order to claim the bonus, the winning rover must also send back images of artifacts located at a previous lunar landing site. The Heritage Bonus has become a controversial aspect of the Lunar X Prize. The rules state that landing plans must be approved by the $\mathrm{X}$ Prize Foundation in advance, "in order to eliminate unnecessary risks to the historically significant sites of interest", but they offer no explanation of what criteria will be used to judge risks as "unnecessary" or what steps, if any, are recommended to competitors to help them avoid damaging sites. Many of the competing teams initially announced plans to attempt to win the Heritage Bonus; at least two of them (Astrobotic and Frednet) made Tranquility Base their target, although those plans eventually changed at NASA's request (see section 2.3 below). The present author has argued elsewhere that the Heritage Bonus should be withdrawn so as to protect historic sites from damage [24]. Google's sponsorship of the competition is highlighted by its Google Earth software, which includes a Moon feature allowing users to make a virtual "visit" to sites such as Tranquility Base. Message boards hosted by the X Prize Foundation and other groups are full of commenters interested in the historic sites and objects on the Moon. Some of these - at least jokingly - hope to lay claim to the artifacts and sell them on eBay (see Appendix 1).

\subsection{The legal disposition of space objects}

Although it is clear that significant heritage resources can be identified in space, there are no legal documents offering protective guidelines for heritage objects in space. As an archaeologist, rather 
than a legal expert, it is not possible for me to present a deeply nuanced discussion of space law here. What is clear, however, is that finding consensus within the international community, as well as to the as-yet unresolved problem of how to enforce laws in space, has generated great difficulty. Controversy even extends to the legal definition of outer space, as distinct from airspace. No international treaty even states where space begins, although Australia has defined $100 \mathrm{~km}$ above sea-level as the lower limit for space for its legal purposes, and this limit may, in the future, become standard [25]. The primary instrument governing the use of space is the 1967 United Nations Treaty on Principles Governing the Activities of States in the Exploration and Use of Outer Space, including the Moon and Other Celestial Bodies (hereafter, the Outer Space Treaty, or OST) [26,27]. This document was joined over the succeeding 12 years by a series of agreements dedicated to problems such as rescue aid for astronauts during an emergency, liability for damage caused by humanmade space objects, the registration of objects placed in space, and activity on the Moon.

The OST makes no mention of heritage. This omission is likely because there were few international protections in place for heritage on Earth at the time of its drafting - the primary treaties concerned with heritage (the UNESCO Cultural Property Convention and the World Heritage Convention, discussed in Section 3.3.1 below) postdate the OST by three and five years, respectively. The most relevant sections of the OST for heritage protection are those that treat property rights, sovereignty, and jurisdiction. Article II of the OST denies the possibility of any state claiming any part of space as its territory. No nation may have sovereignty over space or planetary bodies. Therefore, no government may designate protective status for any territory in space. On the other hand, under Article VIII of the OST, any objects placed in space remain the property of the entity that put them there in perpetuity. There is a recognized dichotomy, then, between sovereignty and jurisdiction. These principles are clearly of prime importance for anyone hoping to exploit (or preserve) heritage resources in space.

One of the UN space treaties does specifically mention heritage, but it refers only to the existing natural environment. The 1979 Moon agreement states that "the moon and its natural resources are the common heritage of mankind" (Article 11). The Moon agreement has found little success - perhaps especially because of Article 11 and its consequences for future commercial exploitation of natural resources. While 101 states have ratified the OST, and another 26 are signatories to it, including all of the states with active space programs, four have merely signed and only 14 have ratified the Moon agreement. The four signatories to the Moon agreement are France, Guatemala, India, and Romania; the fourteen ratifiers are Australia, Belgium, Lebanon, Mexico, Pakistan, Peru, Kazakhstan, Austria, Chile, Morocco, Netherlands, Philippines, Uruguay, and (in March 2012) Turkey. Of these, only two (France and India) have their own active space programs, and neither of those have yet taken steps to implement the Moon agreement within their national laws.

To understand better the threats facing heritage in space, it is worth investigating further the limits of state jurisdiction over objects placed there. Under the OST, the USA, for example, still holds title to, and responsibility for, the objects left behind by the Apollo astronauts on the Moon [28]. The federal government has largely avoided the issue of protection up to this point. A law that went into effect in October 2010 (Public Law No. 111-267, the National Aeronautics and Space Administration Authorization Act of 2010) did establish that Space Shuttle orbiters should be decommissioned "according to established safety and historic preservation procedures" (Section 603). The Space Shuttle orbiters were ultimately awarded to several American cultural organizations in 2011, though each institution has to pay NASA roughly $\$ 29$ million to cover the costs of decommissioning the spacecraft and transporting them to their new homes. The initial House of Representatives version of the legislation (HR 5781) contained language, later removed, which established a system for promoting national and international historic preservation for lunar heritage sites (Section 903). Proponents of space heritage management plan to introduce legislation designating Tranquility Base as a protected site under US federal law in the near future, but given the limits imposed on state sovereignty in space, these protections would have no effect on actors based outside the USA [29]. Similarly, current US law only controls the acts of the US government in orbit or on celestial bodies - there are no restrictions on private activities, American or foreign, undertaken outside the Earth's atmosphere.

Perhaps the most significant step taken by any governmental institution to advance protection for heritage in space came in July 2011, when NASA released a white paper titled "NASA's Recommendations to Space-Faring Entities: How to Protect and Preserve the Historic and Scientific Value of US Government Lunar Artifacts" [30]. This document suggested a 2 km-radius "keep-out" zone for descent/approach near landing sites such as the Apollo and Surveyor missions and a $0.5 \mathrm{~km}$-radius from impact sites such as the Ranger missions. In addition, NASA identified the Apollo 11 and 17 landing sites as eligible for special protection because they were the first and last human landings to date. Hard boundaries of $75 \mathrm{~m}$ radius (for Apollo 11) and 225 m-radius (for Apollo 17) from the lunar module descent stage were suggested for visiting robotic systems. As already noted, the winning rover entry in the Google Lunar X Prize competition needs only to be able to travel $500 \mathrm{~m}$ to claim the main prize. It is hard to see how a private group, relatively inexperienced and poorly funded (by historic standards), could land close enough to a previous landing site to assure that their rover can arrive at such a site while respecting NASA's guidelines. In any event, the recommendations, while a step in the right direction, have no legal force whatsoever, and there is no existing framework to punish anyone who decides to ignore them. Fortunately, participants in the Lunar $X$ Prize competition responded to the NASA white paper by canceling their plans to visit Tranquility Base (although, since the Heritage Bonus is still offered as part of the competition, other previous landing sites remain likely targets).

The states of New Mexico and California, on the other hand, have given some US objects on the Moon legally protected status for their historical significance. California's designation of the Tranquility Base objects as protected was approved in January 2010, with New Mexico's following in April of that year [31,32]. Since no government has jurisdiction over territory in space, state agencies consider only the objects to be protected, not the site. As a symbolic gesture, however, in 2006 New Mexico included Tranquility Base in the state Historic Preservation Division's Cultural Resources Information System as "Site 2,000,000" [33]. Both states cited 106 objects known to have been left at Tranquility Base by Neil Armstrong and Edwin "Buzz" Aldrin. Most of the objects were purposely discarded in order to reduce weight and ensure that the upper half of the Lunar Module Eagle would be able to lift off successfully with its new payload of lunar samples. Other objects, such as the Laser Ranging Retroreflector Experiment (which continues to function), were intended from the beginning to be left behind. Archaeologist Beth O'Leary has recently treated Tranquility Base as an archaeological site, attempting to identify what objects were discarded and to map the area and the discard zone by using NASA records and imagery (see Fig. 1) [34]. In a newspaper interview, O'Leary described the discard process: "[The astronauts] were told to jettison things that weren't important. So they started tossing stuff...They were essentially told, 'Here's 8 minutes, create an archaeology site”' [35]. Some media outlets initially mocked California's and New Mexico's efforts 


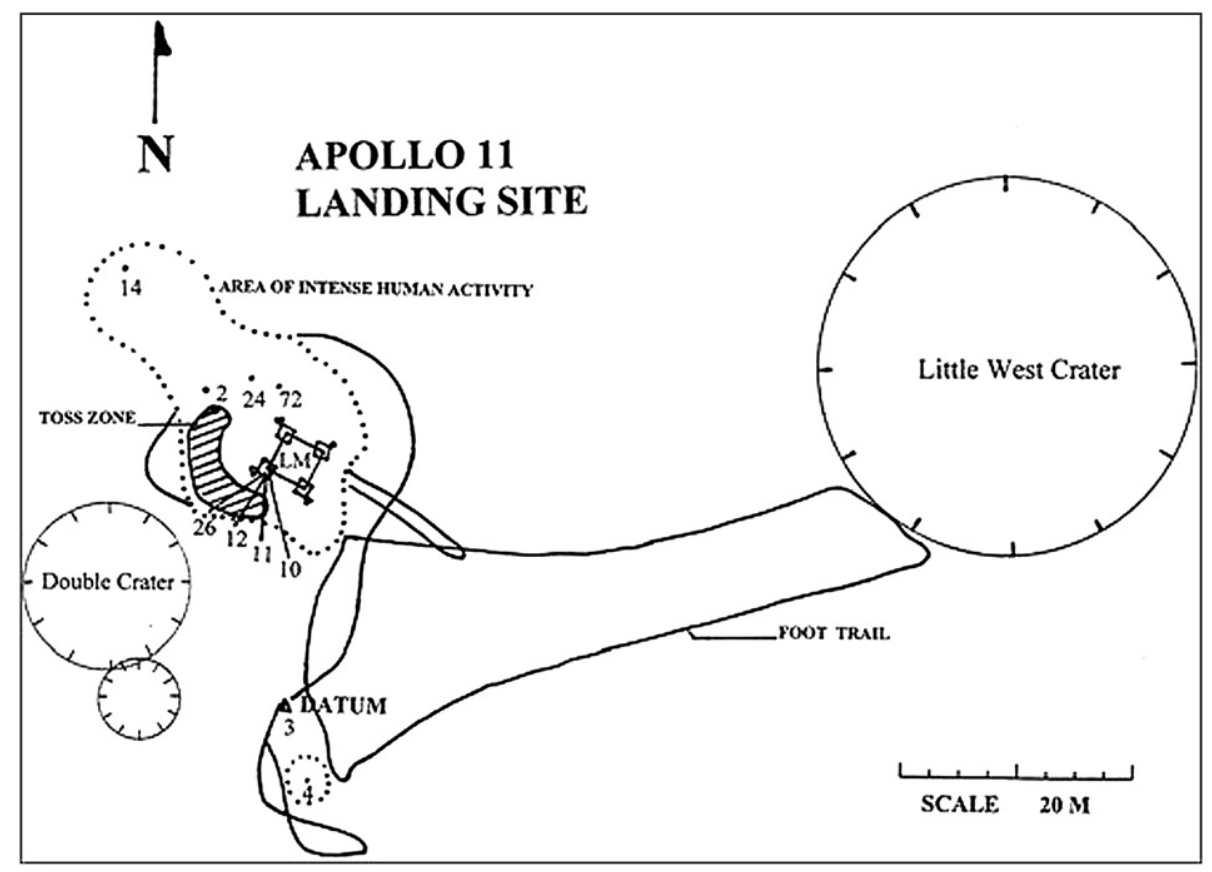

Fig. 1. Site plan, Tranquility Base archaeological site (copyright Beth O'Leary, used by permission).

- in the New York Times, a journalist wrote, "Houston, this is not a joke. I repeat, Houston, this is not a joke," drawing particular attention to the supposedly humorous new standing accorded to two urine-collection devices among the 106 protected objects (more recently, the Times reversed its position in an editorial discussing the NASA recommendations on "keep-out" zones [36,37]). Yet these states and their citizens do see Tranquility Base and its associated objects as significant components of their scientific heritage. They justified the granting of protected status on the basis that many of the contractors who developed the Apollo equipment, and the military bases where NASA conducted preparative tests, were located within their borders.

As a final note regarding the protection of Apollo landing sites, it is worth considering (as Spenneman has done) what status can be accorded to the protection of human footprints in the lunar soil [28]. Many of them are likely to be well-preserved, and thus they offer clear evidence of the movements of astronauts around the sites where they are located. But footprints are not objects - rather, they exist as part of the landscape - a territory which, according to the OST, cannot be governed by any nation's laws. It is clear that an international solution is needed for this international problem.

\section{Heritage management}

Before suggesting principles to guide protective practices, this paper will describe the history of the concept of heritage as it has been understood to relate to Earth-based sites and objects. In this way, the priorities and methods of those who study heritage, and especially those whose job it is to manage it, can be understood and applied to space.

\subsection{Historic struggles over heritage}

There are many kinds of heritage - cultural, historic, tangible and intangible - and heritage can be associated with a place, a time, a building, or an object. When heritage specialists describe "cultural heritage," they refer to a thing that has been embedded with symbolic meaning(s) that relate to societal structures, human relationships, language, myth, or behaviors. Historic heritage can be seen as a subset of cultural heritage, because it consists of things given meaning for their connection with important events in the past. Innovative space objects have both specific historic associations and broader cultural meanings. For example, the launch of Sputnik was historic because it was the earliest example of a human object put into space, but it also had cultural significance within the political context of the Cold War.

Even in the earliest historic times, cultural objects were seen to embody greater meaning than the design, decoration, or raw materials that went into their creation might indicate simply on their own. A well-known basalt pillar displaying the law code of the Babylonian ruler Hammurabi, today in the Musée du Louvre (inv. Sb 8 , dated to ca. 1792-1750 BCE), is one useful example. Originally installed during the king's reign, probably at Sippar, in modern-day central Iraq, the pillar was discovered by a French archaeologist roughly $350 \mathrm{~km}$ away at the Elamite site of Susa, in Iran. The pillar seems to have been captured some 600 years after its creation when Elamites invaded Babylonian territory in the 12 th century BCE. It was subsequently placed on display at Susa as a trophy. Elamite possession of their enemies' ancient monument became symbolic of their control of far-away territory as well as of divine favor for their war. The current location of the pillar in Paris, far from its Iranian findspot, is likewise a clear expression of modern imperialist practices.

Heritage objects have continued to play an important role in international relations. The earliest attempt by a modern nation to reclaim its cultural heritage is perhaps the ongoing Greek effort to recover the Parthenon Marbles. These sculptures, carved in Athens under the supervision of the master Pheidias between 437 and 432 BCE, were removed from the Parthenon by agents working on behalf of the British ambassador to the Ottoman royal court, Lord Elgin, between 1801 and 1812 (Greece was still a part of the Ottoman Empire at the time). Elgin later sold the marbles to the British Museum, where they have been on display ever since. Although Elgin claimed to have secured permission from the local Turkish administrator in Athens to remove the sculptures, one of the first acts of the Greek state following its independence in the 1830 s was to make a formal request for their return [38]. The British 
Museum and the UK government have firmly resisted such restitution, claiming that they hold legal title to the sculptures.

While the dispute over the Parthenon Marbles persists to this day, instances of international cooperation to restore objects and monuments to their original homes are numerous and increasing. Important examples include the return of the Greek vase known as the Euphronios Krater in 2006 by the Metropolitan Museum of Art and the statue called the "Morgantina Goddess" by the J. Paul Getty Museum in 2010, both to the Republic of Italy [4]; the recovery of many artifacts stolen from the National Museum of Iraq in the aftermath of US forces' capture of Baghdad in April 2003 [39,40]; and the conservation and restoration of the Obelisk of Axum by Italy to Eritrea in 2008 [41]. These cases, and many others not listed here, help illustrate how cultural heritage has taken on significance in foreign relations between states as well as in the media. Implicit in that significance is a new interest in cultural heritage on the part of the global public.

\subsection{The importance of protecting archaeological sites}

As both academic and public opinion began to shift during the 20th century toward broadly held respect for all cultures, not only those that were politically and economically powerful, and as the potential (or actual) consequences for cultural patrimony of the modern phenomenon of "total war" became clear, governments reacted by drafting new protective treaty regimes $[1,42,43]$. Archaeologists, in particular, drew attention to problems of destruction as they developed new techniques for unearthing and studying artifacts and architecture. The social science of archaeology is concerned with understanding the totality of human experience. For the most part, archaeologists are interested in past peoples and events, although all times and all places, including the present, offer opportunities for archaeological study. ${ }^{1}$

Obviously, one of the primary methods by which archaeologists learn about their subject is through excavation. The principal tenet of good excavation practice adopted by archaeologists is to delay removal of objects from the ground until it is absolutely necessary to take them out. The reasoning behind this methodology is threefold. First, each archaeological site is unique. Once a site has been excavated, it cannot be re-excavated. Removal of the soil matrix in which artifacts are found is equivalent to its destruction. In other words, excavation can be seen as an unrepeatable experiment. Second, objects that are buried face no immediate threat to their integrity. Leaving them in the ground as long as possible thus contributes to their survival. Finally, archaeologists rely on context as their most important interpretative tool. Accurate recording of the position of artifacts (depth in the soil, location within a particular soil stratum, etc.) is critical for our understanding of the relationship of finds to one another and to architecture, activity areas, or the surrounding landscape.

Illicit excavations of the sort that have been common in many countries over the past century or more, of course, do not record contextual data. Even worse, they eradicate stratigraphic contexts forever, making understanding of the ancient cultures represented by looted sites all but impossible. Similarly, construction of new buildings without archaeological intervention can destroy sites and objects. For mistakes to be minimized, and for all possible data to be collected for analysis, great care and professional expertise are required. The archaeological record is finite, and improved methods of excavation are continually being developed, so many archaeologists now elect to leave sections of their sites unexcavated, for future researchers with

\footnotetext{
${ }^{1}$ One current effort in experimental archaeology is the Tucson Garbage Project, which samples the refuse discarded by inhabitants of that city on a weekly basis for evidence of a wide variety of behaviors such as shopping and eating [44].
}

better techniques to investigate. In a similar fashion, art conservators who work to preserve or restore artworks and artifacts use minimally invasive or even fully reversible techniques where possible.

The looting of sites to produce valuable artworks for the collectors' market is thus an enormous threat to study of the ancient human past [45-47]. The illicit art market is regularly estimated to constitute the third largest international black market, after arms and drugs, and no region of the inhabited world is immune to the problem of looting of cultural heritage [48]. Archaeologists and arts professionals have also recognized how archaeological sites can be compromised for political, religious, or commercial reasons: the explosive demolition of the Bamiyan Buddhas by the Taliban in Afghanistan in 2001, the destruction of the Babri Mosque in the Indian town of Ayodhya by Hindu rioters in 1992 , or the construction of a Wal-Mart superstore adjacent to the archaeological site of Teotihuacán in Mexico in 2004, are just three recent examples. Such destruction eliminates important ways of understanding the past - not only of the objects themselves, but even of the landscapes (and the feelings and sensations) associated with them. In addition to UNESCO, non-governmental organizations such as the International Council on Museums and Sites (ICOMOS), the International Centre for the Study of the Preservation and Restoration of Cultural Property (ICCROM), and the International Committee of the Blue Shield, joined by professional organizations such as the Archaeological Institute of America, the European Association of Archaeologists, and the Register of Professional Archaeologists, have now implemented strong policies and programs to assist in the protection of global heritage.

\subsection{Protocols for protecting heritage on Earth}

\subsubsection{The 1970 UNESCO Convention on Cultural Property and the 1972 UNESCO World Heritage Convention}

Many governments of nations that have historically served as sources of movable cultural heritage, such as India, Thailand, Peru, Mexico, Greece, and Italy, have instituted severe sanctions for looting and destruction of sites, and for the export of heritage objects. In some cases they have gone so far as to define all newly discovered objects of cultural significance, whether on (or in) public or private ground, as belonging to the state. The Republic of Italy's Law 1089 of 1939 was a model for other legislation, defining newly discovered "beni culturali" (cultural goods) as the property of the state. Importantly, this law was superseded in 1999 by legislative decree 490, which added "technical and scientific instruments" to the list of possible cultural goods.

Source nations have also appealed for assistance to historic "market," or "collector" nations, whose citizens and museums have tended to consume the heritage of other (often less powerful or more easily exploited) groups. Repatriation efforts, as noted above, have been aided by the creation of international treaty regimes and other agreements, as well as by policy statements by professional scholarly organizations and cultural institutions. The UNESCO Convention on the Means of Prohibiting and Preventing the Illicit Import, Export and Transfer of Ownership of Cultural Property, created in response to source nations' call for help, has become the critical international protocol on the subject of earthbound cultural heritage (the UNESCO convention was not the first international agreement on the subject of cultural heritage; it was preceded by the 1954 Hague Convention for the Protection of Cultural Property in the Event of Armed Conflict). It was presented for ratification on 14 November 1970 , a date which is now taken by most arts professionals as an important boundary for the appropriate acquisition of artworks which have no documented findspot. Many cultural organizations' codes of ethics state that such unprovenanced artworks may be safely collected only if they first appeared 
on the open market or in publications prior to the convention's ratification. Works that do not meet this standard are considered likely to be the product of looting.

The convention privileges historic scientific objects just as it does artistic ones. It defines "cultural property" as "property which, on religious or secular grounds, is specifically designated by each State as being of importance for archaeology, prehistory, history, literature, art or science" (Article 1). Of particular importance is the fact that the first two subtypes of cultural property listed in the convention are scientific, rather than the artistic or archaeological categories that might have been expected: on the one hand, collections of natural specimens, and on the other, "property relating to history, including the history of science and technology and military and social history, to the life of national leaders, thinkers, scientists and artists and to events of national importance" (emphasis added).

The Cultural Property Convention was joined in 1972 by the World Heritage Convention. This document has become fundamental for heritage management, as it created a World Heritage Committee, formed of a rotating group of 21 of the state parties to the convention (Articles 8-9), which adjudicates the natural and cultural sites that are eligible for enrollment in the World Heritage List (mentioned in Section 1 above). The convention concentrates primarily on sites and architecture, although it also includes in its definition of cultural heritage "elements or structures of an archaeological nature, inscriptions, cave dwellings and combinations of features, which are of outstanding universal value from the point of view of history, art or science" (Article 1). It made individual nations responsible for instituting protective practices that would maintain sites that were placed on the list. Nations with designated World Heritage Sites are required to make reports to the Committee regarding the manner in which they have implemented the convention (Article 29). The World Heritage Committee can also designate sites for a list of "World Heritage in Danger"; there are currently 35 such sites around the world which are threatened by neglect, looting, natural disaster, war, or some other cause [49].

\subsubsection{Other international protocols}

The definition of cultural property found in the 1970 UNESCO Convention provides a starting point for understanding what objects and sites qualify for protection. Other existing legal regimes, particularly the Law of the Sea and the Antarctic Treaty, are also useful, for a variety of reasons, to the question of preserving extraterrestrial heritage. The potential applicability of the concepts behind these treaties to the context of space is not an original suggestion, but in previous discussions the focus has remained on commercial exploitation of space and planetary protection, rather than on preservation of heritage [50,51]. In both sets of agreements, the problem of heritage sites and objects that are in international, rather than national, territories is considered. The relative difficulty of reaching sites and objects underwater or in Antarctica is also a point of similarity, as is the fact that nation-states, rather than individuals, are generally seen as the primary actors, just as they are in space science and exploration. Finally, just as in space, the underwater and Antarctic contexts in which cultural heritage is found tend to be the domain of scientific research, rather than of commercial exploitation or other activities - although tourists and private corporations are increasingly encroaching on those contexts (see Appendix 2). The specific details of the following international protocols might be of variable relevance, in some respects, to the problems associated with cultural heritage protection in space, but the principles they represent and the examples they offer for future development will be critically important.

3.3.2.1. The Law of the Sea and the 2001 UNESCO Convention on Underwater Cultural Heritage. A system of law for international waters was developed over the course of the 20th century, ultimately leading to the adoption of the 1982 United Nations Convention on the Law of the Sea. The question of underwater cultural heritage was largely ignored in this agreement, apart from a brief mention in Article 303: "States have the duty to protect objects of an archaeological and historical nature found at sea and shall co-operate for this purpose." This principle was expanded in a more recent treaty, the 2001 UNESCO Convention on the Protection of the Underwater Cultural Heritage. This agreement, which entered into force once 20 nations had joined it in early 2009, covers all culturally or historically significant material that has been submerged for at least 100 years. In accordance with good-practice principles for archaeology and conservation (see Section 3.2 above), the treaty emphasizes in situ preservation over salvage (Article $2(5)$ ). It also places responsibility in the hands of state parties to ensure that commercial exploitation of heritage sites is avoided, and that even incidental damage to sites is mitigated or prevented (Article 2(7) and Article 5). Finally, "responsible non-intrusive access to observe or document in situ underwater cultural heritage shall be encouraged to create public awareness, appreciation, and protection of the heritage except where such access is incompatible with its protection and management" (Article 2(10)).

3.3.2.2. The Antarctic Treaty. Although several nations have made claims on some or all of the territory of Antarctica, the management of the continent is today done under a 1959 international agreement among those states that have participated in scientific research there: the Antarctic Treaty [52]. Territorial claims are put on hold by this agreement. There are two points of significance regarding the treaty: first, the UN was not involved in its composition, so it considers only the rights of countries involved in Antarctic research to participate in the management of Antarctica; second, the document is clear that the activities to be carried out in Antarctica are to be of a scientific nature-military activity is prohibited there. Further, any nation that is party to the treaty may inspect the facilities of any other nation at any time, establishing a system of checks on potentially illicit behavior (Article VII(1) and (3)).

The most significant addition to the Antarctic Treaty with regard to heritage management is the 1991 Environmental Protection Protocol (EPP) and its six annexes. As the protocol's name implies, it outlines the various ways in which parties to the Antarctic Treaty are responsible for protecting the continent's environment. It also sets up a regulatory body and system of rules to be followed. Fundamentally for the EPP's role of guiding the development of cultural heritage protections in space, it specifically includes areas of historic significance in its definition of aspects of the environment which merit special status. Article 3(2) of the EPP states that "activities in the Antarctic Treaty area shall be planned and conducted so as to avoid... degradation of, or substantial risk to, areas of biological, scientific, historic, aesthetic or wilderness significance." Casarini has made an excellent catalog of historic activities which might have left traces in the Antarctic archaeological record [53]. The concept of protecting historic sites is developed further in the protocol's annexes. ${ }^{2}$ EPP Annex V ("Area Protection and Management") lays out two tiers for protected sites and monuments:

\footnotetext{
2 In addition to EPP Annex V, discussed in detail below, EPP Annex III ("Waste Disposal and Waste Management") mentions cultural heritage briefly. Article 1(5) states that "Past and present waste disposal sites on land and abandoned work sites of Antarctic activities shall be cleaned up by the generator of such wastes and the user of such sites. This obligation shall not be interpreted as requiring...the removal of any structure designated as a historic site or monument." Article 3(2) orders that the burning of waste should be planned so as to avoid having particulates land "over areas of special biological, scientific, historic, aesthetic or wilderness significance including, in particular, areas accorded protection under the Antarctic Treaty."
} 
Specially Protected Areas and Specially Managed Areas. According to Article 3(1) of this annex, "any area, including any marine area, may be designated as an Antarctic Specially Protected Area to protect outstanding environmental, scientific, historic, aesthetic or wilderness values, any combination of those values, or ongoing or planned scientific research." Entry to an Antarctic Specially Protected Area without a permit is prohibited (EPP Annex V, Article $3(4)$ ). The other type of designation for site protection is at a lower level: the Antarctic Specially Managed Area (EPP Annex V, Article 4). No special permit is required for visits to a Specially Managed Area. The power to determine whether to designate a site for protection, and what level of protection is appropriate falls to the Committee on Environmental Protection (EPP Annex V, Article 6). This committee, established by the protocol, is comprised of one representative from each of the parties to the EPP (Article 11).

Maintenance plans for designated sites are required from the group applying for protected status for a site at the time of application, and, following confirmation of the designation by the Committee, the plans must be updated every five years. The applicant for designation may be one of the parties to the treaty, the Scientific Committee for Antarctic Research, the Commission for the Conservation of Antarctic Marine Living Resources, or even the Committee on Environmental Protection itself (EPP Annex V, Article 5). Among other points, management plans must regulate "access to and movement within or over the area... [and] the collection or removal of anything not brought into the area by the visitor." At least one legal scholar has made suggestions for a checklist to be used during inspections of Antarctic outposts [54].

\section{Future efforts to protect space heritage}

\subsection{Suggestions for development}

It is not necessary to create an international protocol for the protection of spacebound cultural heritage from scratch [55]. The treaties regarding cultural heritage on Earth described in Section 3 can be useful models for developing an effective space treaty. The first order of business will be to determine what features are desired in a protective scheme.

\subsubsection{Summary of relevant points in the available international models for protecting cultural heritage}

Each of the documents described in Section 3 took a slightly different approach to the question of cultural heritage protection. The following list collects the most useful components of each for protecting extraterrestrial heritage:

1. Definition of the kinds of objects and sites, including innovative scientific instruments, that are eligible for protection (Cultural Property Convention and World Heritage Convention).

2. Support for international cooperation to protect heritage for all humanity (all of the treaties).

3. Inclusion of otherwise disenfranchised groups in discussions of protection (the Cultural Property Convention and the Outer Space Treaty).

4. Emphasis on in situ preservation rather than removal of heritage (Underwater Heritage Convention).

5. Responsible observation and documentation of heritage in order to increase public awareness and appreciation (Underwater Heritage Convention).

6. Creation of an international body to designate and monitor protected status (World Heritage Convention and Antarctic Treaty).

7. Development of multiple levels of protected status (Antarctic Treaty).
8. Enabling of a transparent protection scheme by opening the planning of site and object management to international scrutiny (World Heritage Convention and Antarctic Treaty).

\subsection{A new protocol for protecting space heritage}

Clearly, the range and quantity of equipment left in space means that there is too much already there for everything to be protected (were that even a desired goal). The Antarctic Treaty, however, recognizes that not all objects need to be protected, thus there may even be merit in creating a tiered system of protective statuses in space. Some sites might be regarded as visitable by the general public (i.e. space tourists), while others might be available only to scholars, or even off-limits entirely until appropriate techniques can be developed for their management. Tranquility Base, for example, must rank at or near the top of any reasonable list, but there will be differing opinions about other sites and objects. A responsible international Heritage Protection Committee (HPC) should therefore be established, similar to the UNESCO World Heritage Committee and the Committee for Environmental Protection in Antarctica, which will receive nominations, judge their relative importance and need, and oversee management of sites and objects that receive protective status. This committee would be created most appropriately under COPUOS, the standing body of the United Nations for space affairs. The proposed HPC should be composed of members representing as many different types of stakeholders as possible - space scientists, cultural heritage specialists, and diplomatic representatives from governments of both spacefaring and non-spacefaring nations. The inclusion of this last group will be critical under the principle established by the OST that "the exploration and use of outer space should be carried on for the benefit of all peoples irrespective of the degree of their economic or scientific development." In this sense, at least, the proposed framework is closer to the UNESCO conventions than to the Antarctic Treaty. The groups petitioning the HPC will in all likelihood be the nations that registered the objects following their launch (e.g. the USA for Tranquility Base, or one of the nations that emerged from the former Soviet Union for Luna 2, the first spacecraft to land on the Moon, in 1959), and these groups could also develop and administer appropriate protective plans under the supervision of the HPC.

The Convention on the Protection of the Underwater Cultural Heritage shows how certain other important values regarding historic preservation can also be enshrined in international agreements. Specifically, one directive derived from ethical professional practice (that objects be preserved in situ rather than removed from their protective environment), and another reflecting the need for public support (that responsible research be encouraged in order to draw positive attention to cultural heritage) can be taken as guidelines for the proposed HPC and for states managing designated sites to follow.

\subsection{Planning for post-operational phases of missions}

Another aspect of cultural heritage protection that ought to become part of standard practice is improved mission design [56]. For some time, it has been apparent that planning for the postfunctional life of space objects is lacking. The Soviet space station Mir is perhaps the best example. Following the enormous contributions made to space research at the station over the course of its extended life of 15 years, the later Russian space administration was unable to devise a plan to preserve Mir for posterity. It was therefore purposely de-orbited on 23 March 2001, partly burning up during atmospheric re-entry and falling into the Pacific Ocean. This is not a sustainable method for removing orbiting objects from service, if only from an environmental perspective - there is 
already a large amount of human debris in the Earth's oceans, as evidenced by phenomena such as the Great Pacific Garbage Patch [57].

The Hubble Space Telescope, another innovative and historically significant piece of technology, potentially faces a similar fate sometime after its successor, the James Webb Space Telescope, is placed in orbit around 2014. Only following deployment of Hubble did NASA began to consider seriously the challenge of preservation. The agency intended to develop and install a "de-orbit mechanism" that would return the device safely to Earth. Although this plan was eventually rejected because of its cost, the final Hubble service mission in 2009 did include the installation of a "Soft Capture Ring" that would allow for easier retrieval at an unspecified later date. Some scholars have suggested the possibility of placing Hubble or other historically important objects following their decommissioning at one or another of the Lagrange points for their preservation [58]. Such "parking" of historic satellites on a longterm basis would even provide the opportunity for study of the effects of the solar wind and other forces on sensitive equipment. On the other hand, it is also clear that space at these points is limited and probably in high demand for other scientific uses. Reservation of relatively empty low-Earth orbital altitudes by international agreement for the placement of heritage satellites might present a possible solution, however.

Mission planners might protest that increased costs related to post-operational preservation and protection pose an unnecessary burden. The problems associated with preserving the Hubble telescope, however, should serve as an adequate example of how good planning in advance makes greater economic sense. Setting welldefined goals from the beginning for the post-operational phase of the Hubble mission - which from the outset was obviously an important project - would have saved NASA the later costs of first making and then scrapping plans for de-orbiting the telescope, as well as the post-launch design and installation of a new retrieval device.

Economic considerations aside, historic preservation should be no different from other kinds of environmental protection as an ethical concern $[59,60]$. The mere location of extraterrestrial heritage cannot preclude it from proper treatment according to modern standards, as described in section 3.2 above. Further, the international treaties and national regulations discussed earlier show that protection of heritage is considered by governments, nongovernmental organizations, and the public to be a high priority. Nine and a half million people each year choose to go to the National Air and Space Museum as part of their hard-earned leisure time because they are deeply interested in the achievements of the past - and the possibilities of the future.

I therefore suggest that mission planners can mobilize greater support for their projects by placing their proposed research in a larger historical context. Creating and publicizing plans for the post-operational stages of a mission to include a strategy for the preservation, study, and even display of the equipment and/or site can become a useful means of engaging with the public, which, in turn, could yield access to greater funding. At the same time, missions that make accommodations for heritage protection can be incentivized in two ways: by strong new policy statements and protocols established by professional organizations including the International Academy of Astronautics and the Committee on Space Research; and through rules created by granting institutions such as national science ministries and private foundations. It is hoped that some mention of heritage management will become a standard part of all research grant proposals, in precisely the same way that environmental impact statements are now common. Not all missions will be likely to deserve historic status designation, of course, and those that are less likely to do so can accordingly devote fewer resources and attention to the heritage component of their post-operational phase (though the appropriate and sustainable disposal of equipment should still be a point of interest).

\section{Conclusion: "the future as human heritage" [61]}

It is worth stating clearly that archaeologists and other cultural heritage specialists do not hope to prevent other scholars from conducting research. The issue at stake in this paper is simply that whatever future actions are taken in space, their consequences for the damage of significant existing sites and objects must be considered [28,62]. At least one space researcher has already raised appropriate alarms about the threat posed by commercial activity, including tourism, to the environments of celestial bodies. He has even proposed rescue archaeology as a model for space researchers designing protective schemes [63]. Others have likewise proposed a system of "parks" to preserve the environments of celestial bodies, a proposal similar in some ways to that put forward here, though lacking the specific and long-standing international precedents provided by the treaties described above [28,64].

From the long perspective of an archaeologist, human endeavors in space are still in their infancy. There should be no heedless rush to send either manned or unmanned missions back to the sites where humans first interacted with celestial bodies. By the same token, the sooner an active management regime is put in place to protect cultural heritage, the better our chances will be of preserving what remains for future generations to study and appreciate. Experience with Earth-bound sites has shown that even a well-intentioned expedition to a site could alter the material record irrevocably and with unforeseen results. More specifically, the new protective status recently granted by California and New Mexico to the objects at Tranquility Base should give pause to researchers and private interests hoping to visit that site and others. While the extent to which those states are able to prosecute offenders who reside outside their borders remains unclear, much of the field of space research - and, indeed, space tourism and private spaceflight, with the recent opening of Spaceport America outside Las Cruces, New Mexico - has strong ties to companies and research centers in those states. The X Prize Foundation and Google, both of which are headquartered in California, may well find it in their best interests to rethink the Heritage Bonus of the Lunar X Prize and the possibility that a team taking part in their competition could inadvertently dislodge, damage, or destroy heritage objects.

Although no current international framework exists to direct public and private actors in space about how to deal with historically significant objects and sites, clear guides exist that could be used to develop such a framework. These guides are the current terrestrial conventions and treaties that define cultural heritage in international territories and which outline the steps to be taken by nations to protect it. There are particularly close comparanda to be found in the heritage sections of the treaties under the high seas and on Antarctica, which resemble space by virtue of their international character, remoteness, and environmentally pristine nature. By taking cues from these existing agreements, it is possible to establish an effective Heritage Protection Committee that can evaluate claims and oversee the management of heritage. Space scientists can do their part by instituting new policies and practices that take into account the post-operational phase of their missions, and by engaging with a public that is passionate about the human exploration of space.

\section{Acknowledgments}

This paper benefited substantially from the wise comments of several readers, who are heartily thanked: the anonymous reviewers for Space Policy; the journal editor, Frances Brown; Frans 
von der Dunk, who gave advice regarding space law; Mark Zucker, who proofread an early draft; Beth O'Leary, who gave notes on current and prior cultural heritage efforts in space; and Vera Fernandes, who helped me to formulate my arguments and format the paper for a space-research audience. Finally, I thank Jill Thomas, whose interest in this problem during a graduate seminar in 2008 sparked my own exploration of possible solutions. Any errors remain the responsibility of the author alone.

\section{Appendix 1}

In one X Prize forum online, a user named VAXHeadroom joked on 23 July 2008, "I just want the golf balls [used by astronaut Alan Shepard during the Apollo 14 mission] so I can put them on eBay" [65]. On a Slashdot forum, the user NotQuiteReal wrote on 22 July 2009, "Now, if you could dig [the soil containing astronauts' footprints] up and bring them back, along with some other artifacts, now that would be worth something! Do regular international salvage laws apply to abandoned Moon gear?" Another user, called Tubal-Cain, responded, "I would think that no laws apply in space [emphasis in the original]. Sure, we have the Moon treaty, but that's hardly a paninternational [sic] agreement. The only rules that apply are those that others have the ability and will to enforce. Both factors severely reduce the number of people that will bother you up there. Of course, if you upset enough people, you might not want to try coming back" [66].

\section{Appendix 2}

A recent newspaper report described the desire of tourists to recreate early expeditions to the South Pole [67]. While annual Antarctic tourism numbers have dropped off from a high of over 46,000 since the global economic recession began in 2008, many people were drawn by the centennial of Roald Amundsen's arrival at the South Pole on 14 December 1911. As the article stated, "Some people intend to ski the exact routes of Amundsen and Scott, reading the explorers' diaries daily and blogging about the experience. Others will drive to the pole by truck. For those seeking less exertion, there will be catered flights to the pole, including several that will let passengers off a few miles away so they can ski the remaining stretch and feel the thrill of victory." It is easy to imagine tourists being offered similar opportunities to visit Tranquility Base for the Apollo 11 centennial in 2069.

\section{References}

[1] Brown MF. Who owns native culture? Cambridge, MA: Harvard University Press; 2003.

[2] Cuno J. Who owns antiquity? Museums and the battle over our ancient heritage. Princeton, NJ: Princeton University Press; 2008.

[3] Fitz Gibbon K. Who owns the past? Cultural policy, cultural property, and the law. New Brunswick, NJ: Rutgers University Press; 2005.

[4] Isman FI. Predatori dell'arte perduta: il saccheggio dell'archeologia in Italia. Milan: Skira Edizioni; 2009

[5] Mackenzie SRM. Going, going, gone: regulating the market in illicit antiquities. Leicester: Institute of Art and Law; 2005.

[6] Mauch Messenger P, editor. The ethics of collecting cultural property: whose culture? Whose property?. $2^{\text {nd }}$ ed. Albuquerque: University of New Mexico Press; 1999.

[7] Stille A. The future of the past. New York: Picador; 2003.

[8] Watson P. Sotheby's: the inside story. New York: Random House; 1997.

[9] Watson P, Todeschini C. The medici conspiracy: the illicit journey of looted antiquities from Italy's tomb raiders to the world's greatest museums. New York: Public Affairs; 2006

[10] Felch J, Frammolino R. Chasing Aphrodite: the hunt for looted antiquities at the world's richest museum. New York: Houghton Mifflin Harcourt; 2011.

[11] World Heritage List (http://whc.unesco.org/en/list, accessed 20 March 2012).

[12] United States Space Object Registry (http://www.usspaceobjectsregistry.state. gov/registry/dsp_DetailView.cfm?id=2, accessed 20 March 2012).
[13] Kawamoto S, Nishida S, Kibe S. Research on a Space Debris Removal System, no date (online at http://airex.tksc.jaxa.jp/dr/prc/japan/contents/NALRP2003032/ nalrp2003032.pdf, accessed 20 March 2012).

[14] Cleaning up Earth's orbit: a Swiss satellite tackles space debris, 15 February 2012 (online at http://actu.epfl.ch/news/cleaning-up-earth-s-orbit-a-swisssatellite-tack-2/, accessed 8 March 2012).

[15] Chang K. For space mess, scientists seek celestial broom. The New York Times 18 February 2012.

[16] US Strategic Command (online at http://www.stratcom.mil/factsheets/ USSTRATCOM_Space_Control_and_Space_Surveillance/, accessed 20 March 2012).

[17] Kluger J. The bloc on the block. Discover Magazine April 1994.

[18] Launius RD. The historical dimension of space exploration: reflections and possibilities. Space Policy 2000;16:23-8.

[19] Goodman MS. Making space for history. Space Policy 2001;17:229-30.

[20] NASM attendance numbers come from an internal document provided to the author by the museum's Office of Communications, and were generated by the Smithsonian Institution Visit Count Management System (C. Brown, personal communication).

[21] Pes J, Sharpe E. Japanese old master tops the attendance tree. The Art Newspaper 1 April 2011.

[22] The Memorial Museum of Cosmonautics, Museums in Russia - Russian Cultural Heritage Network (official tourist board website, online at http:// www.russianmuseums.info/M329, accessed 20 March 2012).

[23] Google lunar X Prize rules and guidelines, version 3.0, released 20 November 2008.

[24] Thomas J, Walsh JSt P. Don't boldly go there. The Los Angeles Times 1 June 2009.

[25] Lyall F, Larsen PB. Space law: a treatise. Farnham: Ashgate Publishing; 2009.

[26] Doyle SE. International space community and space law. In: Darrin A, O'Leary BL, editors. Handbook of space engineering, archaeology, and heritage. New York: CRC Press; 2009. p. 741-55.

[27] Bini A. The moon agreement in the 21st century. Acta Astronautica 2010;67: 496-501.

[28] Spenneman DHR. The ethics of treading on Neil Armstrong's footsteps. Space Policy 2004;20:279-90 (espp. 286-7).

[29] Westwood L. Personal communication.

[30] The NASA document is archived online at http://www.collectspace.com/ news/NASA-USG_lunar_historic_sites.pdf (accessed 20 March 2012).

[31] State of California Department of Parks and Recreation Primary Record sheet available online at http://ohp.parks.ca.gov/pages/1067/files/tranquility\%20base_ draft.pdf, accessed 14 November 2010.

[32] New Mexico Department of Cultural Affairs Historic Preservation Division file \#1946 (http://www.nmhistoricpreservation.org/assets/files/registers/PropertiesByCounty. pdf, accessed 20 March 2012).

[33] Tranquility Base Tied to State Museum of Space History, online at http://www. nmspacemuseum.org/content.php?id=225, accessed 20 March 2012.

[34] O'Leary BL. One giant leap: preserving cultural resources on the moon. In: Darrin A, O'Leary BL, editors. Handbook of space Engineering, archaeology, and heritage. New York: CRC Press; 2009. p. 757-79.

[35] Anton M. Putting the moon in the state's orbit. The Los Angeles Times 29 January 2010.

[36] McKinley K. To California, moon junk is state treasure. The New York Times 29 January 2010.

[37] That old heritage moon (editorial). The New York Times; 20 September 2011.

[38] St. Clair W. Lord Elgin and the marbles. $3^{\text {rd }}$ ed. Oxford: Oxford University Press; 1998. For the earliest request by Greece for restitution, see esp. p. 333

[39] Bogdanos M, Patrick W. Thieves of Baghdad. New York: Bloomsbury Press; 2005. ch. 7-14.

[40] Stone P, Bajjaly JF, Fisk R, editors. The destruction of cultural heritage in Iraq, heritage matters series. Rochester: Boydell Press; 2008.

[41] Nadotti C. Axum, la stele è tornata dov'era; in 30 mila per festeggiare l'evento. La Repubblica 4 September 2008.

[42] Karp I, Levine SD. Exhibiting cultures: the poetics and politics of museum display. Washington: Smithsonian Institution; 1991. esp. Parts 3 and 5.

[43] Nicholas L. The rape of Europa: the fate of Europe's treasures in the third Reich and the second world war. New York: Vintage; 1994.

[44] Rathje WJ, Murphy C. Rubbish! The archaeology of garbage: what our garbage tells us about ourselves. New York: Harpercollins; 1992.

[45] Brodie N, Doole J, Renfrew C, editors. Trade in illicit antiquities: the destruction of the World's archaeological heritage. McDonald Institute Monographs. Cambridge: Cambridge University Press; 2001.

[46] Renfrew C. Loot, legitimacy and ownership. In: Duckworth debates in archaeology. London: Duckworth; 2000.

[47] Gill DWJ, Chippindale C. Material consequences of esteem for cycladic figurines. American Journal of Archaeology 1993;97:601-59.

[48] Cleere H, editor. Approaches to the archaeological heritage. New directions in archaeology. Cambridge: Cambridge University Press; 2009.

[49] World Heritage in Danger List (online at http://whc.unesco.org/en/danger/, accessed 20 March 2012).

[50] Frakes J. The common heritage of mankind principle and the deep seabed, outer space, and Antarctica: will developed and developing nations reach a compromise? Wisconsin International Law Journal 2003;21.2:409.

[51] Race M. Policies for scientific exploration and environmental protection: comparison of the Antarctic and outer space treaties. In: Berkman P, Lang M, Walton D, Young O, editors. Science diplomacy: Antarctica, science and the governance of international spaces. Washington: Smithsonian Institution Scholarly Press; 2011. p. 143-52. 
[52] Antarctic Treaty (online at http://www.ats.aq/, accessed 14 November 2011).

[53] Casarini MP. Activities in Antarctica before the conclusion of the antarctic treaty. In: Francioni F, Scovazzi T, editors. International law for Antarctica. $2^{\text {nd }}$ Ed. The Hague: Kluwer Law International; 1996. p. 627-81.

[54] Giuliani P. Inspections under the Antarctic treaty. In international law for Antarctica $2^{\text {nd }}$ ed. In: Francioni F, Scovazzi T, editors. International law for Antarctica $2^{\text {nd }}$. ed. The Hague: Kluwer Law International; 1996. p. 470-4. editors (esp. 472 on abandoned outposts; the last item on his checklist for these types of sites is "Presence on site or in vicinity of any notable historic artefacts (sledges, skis, ration boxes, etc.)").

[55] von der Dunk FG. The role of law with respect to future space activities. Space Policy 1996; $12.1: 5-8$.

[56] Rogers AQ Darrin A. Mission planning - Space archaeology and preservation planning: system engineering perspective. In: Darrin A, O'Leary BL, editors. Handbook of space engineering, archaeology, and heritage. New York: CRC Press; 2009. p. 801-15.

[57] Kaiser J. The dirt on ocean garbage patches. Science 2010;328(5895):1506

[58] Barclay R, Brooks RC. In situ preservation of historic spacecraft. In: Darrin A, O'Leary BL, editors. Handbook of space engineering, archaeology, and heritage. New York: CRC Press; 2009. p. 679-700.
[59] Viikari LE. The legal regime for moon resource utilization and comparable solutions adopted for deep seabed activities. Adv Space Res 2003;31: 2427-32.

[60] Williamson M. Lunar exploration and development - A sustainable model Acta Astronautica 2005;57:161-6.

[61] Arnould J, Debus A. An ethical approach to planetary protection. Adv Space Res 2008;42:1089-95.

[62] Kleiman MJ. Protecting Apollo artifacts on the Moon. The space review (online at http://www.thespacereview.com/article/1961/1, accessed 8 March 2012).

[63] Collins P. Space tourism: from Earth orbit to the Moon. Adv Space Res 2005; 37:116-22.

[64] Cockell CS, Horneck G. A planetary park system for Mars. Space Policy 2004; 20(4):291-5.

[65] http://spacefellowship.com/Forum/viewtopic.php?f=45\&t=6863\&sid=4f01c 59b01d7f1d99f718b2d1e1e35a2, accessed 20 March 2012

[66] http://hardware.slashdot.org/comments.pl?sid=1312001\&cid=28791115, accessed 20 March 2012.

[67] Kingson JA. Tourists mimic polar pioneers, except with planes and blogs. The New York Times; 16 January 2011. 